\title{
Kinetics modeling of delta-ferrite formation and retainment during casting of supermartensitic stainless steel
}

Nießen, Frank; Tiedje, Niels Skat; Hald, John

Published in:

Materials \& Design

Link to article, DOI:

10.1016/j.matdes.2017.01.026

Publication date:

2017

Document Version

Peer reviewed version

Link back to DTU Orbit

Citation (APA):

Nießen, F., Tiedje, N. S., \& Hald, J. (2017). Kinetics modeling of delta-ferrite formation and retainment during casting of supermartensitic stainless steel. Materials \& Design, 118, 138-145.

https://doi.org/10.1016/j.matdes.2017.01.026

\section{General rights}

Copyright and moral rights for the publications made accessible in the public portal are retained by the authors and/or other copyright owners and it is a condition of accessing publications that users recognise and abide by the legal requirements associated with these rights.

- Users may download and print one copy of any publication from the public portal for the purpose of private study or research.

- You may not further distribute the material or use it for any profit-making activity or commercial gain

- You may freely distribute the URL identifying the publication in the public portal 

during casting of supermartensitic stainless steel

\author{
Frank Niessen $^{1 *}$, Niels S. Tiedje ${ }^{2}$ and John Hald ${ }^{3}$
}

${ }^{1}$ Technical University of Denmark (DTU), Danish Hydrocarbon Research and Technology Centre (DHRTC), Elektrovej building 375, 2800 Kgs. Lyngby, Denmark; frannie@dtu.dk

${ }^{2}$ Technical University of Denmark (DTU), Department of Mechanical Engineering, Produktionstorvet building 427, 2800 Kgs. Lyngby, Denmark; nsti@mek.dtu.dk

${ }^{3}$ Technical University of Denmark (DTU), Department of Mechanical Engineering, Produktionstorvet building 425, 2800 Kgs. Lyngby, Denmark; jhald@mek.dtu.dk

*Corresponding author

Keywords: Kinetics modeling, Delta ferrite, Solidification, Casting, Supermartensitic stainless steel, Diffusion, Solid state transformation

\title{
Abstract
}

The kinetics model for multi-component diffusion DICTRA was applied to analyze the formation and retainment of $\delta$-ferrite during solidification and cooling of GX4-CrNiMo16-5-1 cast supermartensitic stainless steel. The obtained results were compared with results from the Schaeffler diagram, equilibrium calculations and the Scheil model in Thermo-Calc, and validated by using microscopy and Energy Dispersive X-ray Spectroscopy for chemical analysis on a cast ingot. The kinetics model showed that micro-segregation from solidification homogenizes within $2-3 \mathrm{~s}\left(70{ }^{\circ} \mathrm{C}\right)$ of cooling, and that retained $\delta$-ferrite originates from the incomplete transformation to austenite. The kinetics model predicted the measured amount of $\delta$-ferrite and the partitioning of $\mathrm{Cr}$ and Ni reasonably well. Further, it showed that slower cooling for the investigated alloy leads to less retained $\delta$-ferrite, which is in excellent agreement with experimental results.

\section{Introduction}

Since the 1960s, when supermartensitic stainless steels were developed, this type of alloys has found increasing use in many industries [1,2]. Specifically in the offshore oil and gas industry such alloy grades were introduced in the 1990s [3]. Supermartensitic stainless steels combine high strength, good toughness as well as reasonable weldability, and they achieve good corrosion performance with relatively low alloy content $[4,5]$.

The optimal properties of the material, extensively described in Refs. [2,6,7], are obtained by normalizing, leading to martensite transformation, followed by tempering in the inter-critical temperature region, in which both austenite $(\gamma)$ and ferrite $(\alpha)$ are thermodynamically stable. The tempering treatment leads to formation of reversed austenite in a finely dispersed lamellar morphology on grain boundaries of lath martensite. This is accompanied by diffusion of austenite stabilizing elements into austenite, which stabilize this phase to room temperature [8-13]. Since the good 
1 mechanical properties of the alloy depend on this stabilization of reversed austenite, it is 2 vital to control the compositional homogeneity of the initial martensitic microstructure 3 prior to tempering. This is particularly challenging for the cast grades, in which macro4 and micro-segregation and the retainment of $\delta$-ferrite from solidification and cooling 5 can lead to an inhomogeneous initial microstructure $[6,14,15]$.

6 The presence of the $\delta$-ferrite phase can cause severe reduction of toughness and ductility 7 [16,17]. Further, it can locally interrupt the passivation layer through Cr-depletion in 8 martensite and formation of $\mathrm{Cr}$ carbides near $\delta$-ferrite, which leads to degradation of the 9 corrosion resistance [18]. Such inhomogeneity affects the nucleation and growth of 10 reversed austenite during tempering in the inter-critical region [15].

11 In the present alloy grade, $\delta$-ferrite is the first solidifying phase, which partially or 12 completely transforms to austenite during cooling. When retained, it is only possible to 13 dissolve $\delta$-ferrite by extensive heat treatment, which is uneconomical and can lead to 14 undesired grain growth [19]. Addition of Ni can largely suppress the retainment of $\delta$ 15 ferrite but it is expensive and it potentially shifts the martensite start $\left(\mathrm{M}_{\mathrm{s}}\right)$ temperature 16 below room temperature. Previous research demonstrated the influence of the chemical 17 composition and cooling-rate on the retainment of $\delta$-ferrite [20-22].

18 The phase distribution after solidification can be estimated by a variety of available 19 models, such as the lever rule, the Scheil Model [23] and empirical models such as the 20 Schaeffler diagram [21]. These models are easy to apply, but oversimplify the 21 mechanisms during solidification and cooling to different degrees. Less common and 22 more complex models, which can be used for solidification and cooling analysis in 23 casting or welding, are regression analysis and neural networks [24-26]. Both these 24 kinds of models are able to predict residual $\delta$-ferrite contents accurately, but require 25 adaptation for new sets of processing parameters and are not physics based.

26 Since formation and retainment of $\delta$-ferrite mainly occur in a temperature region in 27 which phase transformations are primarily controlled by diffusion, it should be possible 28 to predict the formation and retainment of $\delta$-ferrite by kinetics modeling of diffusion. 29 Moving boundary kinetics models, which predict the kinetics of diffusion controlled 30 phase transformations based on constitutive diffusion and flux balance equations, a set 31 of boundary conditions, and thermodynamics and kinetics databases, can be used for 32 this purpose [27]. The aim of the present investigation was therefore to investigate the 33 applicability of the kinetics model DICTRA on predicting the formation and retainment 34 of $\delta$-ferrite during cooling of GX4-CrNiMo-16-5-1 cast supermartensitic stainless steel. 35 The results obtained by simulation with different cooling rates were related to the 36 results of the conventional models and validated on micrographs and chemical analysis 37 of an ingot. 


\section{Material Characterization}

\subsection{Procedures}

The examined cast material GX4-CrNiMo-16-5-1 with the composition given in Table 1 was cast in a keel block of 230 x 110 x 60/25 mm with bottom filling. The casting was cut horizontally at $40 \mathrm{~mm}$ height to exclude the impurity-rich last solidified material (Figure 1). A cross-section in the center of the bar was cut out, embedded, ground and polished for microstructure characterization. Specimens prepared for light optical microscopy (LOM) were etched in Vilella's reagent [28].

The light optical microscope was an Olympus GX41 bright field microscope. The image analysis for the determination of the amount of $\delta$-ferrite in the microstructure was carried out using the MATLAB Image Processing Toolbox. The micrograph was filtered with a Gaussian filter, the background was determined and subtracted, brightness and contrast were adjusted, and the micrograph was converted to a binary image. Then all connected components in the image were determined and filtered by applying a minimum area criterion. The final step consisted of manual refinement of artefacts and determination of the area-fraction.

A JEOL 5900 scanning electron microscope (SEM) with a tungsten filament was used for imaging and energy dispersive X-ray spectroscopy (EDS). The EDS measurement was carried out on an area map between a set of parallel $\delta$-ferrite stringers with $22 \mu \mathrm{m}$ distance between their centerlines. The area scans were averaged in parallel orientation to the $\delta$-ferrite stringers to yield a one-dimensional composition profile, as described in Ref. [29]. This averaging procedure allowed direct comparison with the results of the one-dimensional kinetics model. The acceleration voltage was $18 \mathrm{kV}$ and the step size for the measurement was $100 \mathrm{~nm}$. The EDS-system was calibrated on pure $\mathrm{Cu}$ as a reference just before acquisition. Under consideration of the spatial resolution limit given by the interaction volume of EDS analysis, the acquired data points were averaged to steps of $500 \mathrm{~nm}$.

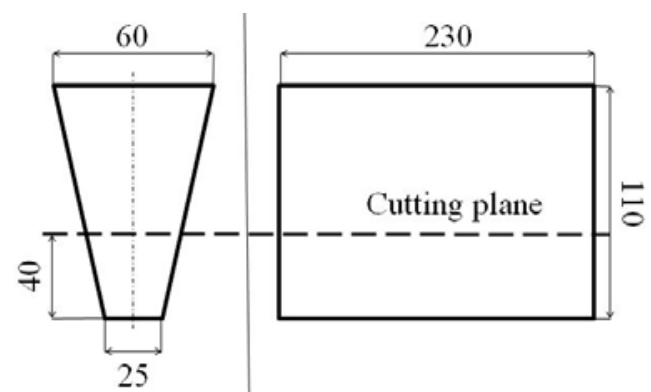

Figure 1 - Geometry of the ingot marking the area of investigation below the cutting plane. Measures are in mm 


\subsubsection{Light optical microscopy}

3 After austenitization the steel consisted of lath martensite and vermicular $\delta$-ferrite 4 [30,31] (Figure 2a). The $\delta$-ferrite was distributed uniformly over the entire 5 microstructure with varying spacing of approx. 15 to $50 \mu \mathrm{m}$ and changed to a lace-like 6 morphology near the surface of the casting. The area fraction of $\delta$-ferrite was 7 determined as $11 \%$ by using image analysis (Figure 2b). The statistical error of this 8 analysis is estimated to be $\pm 2 \%$.
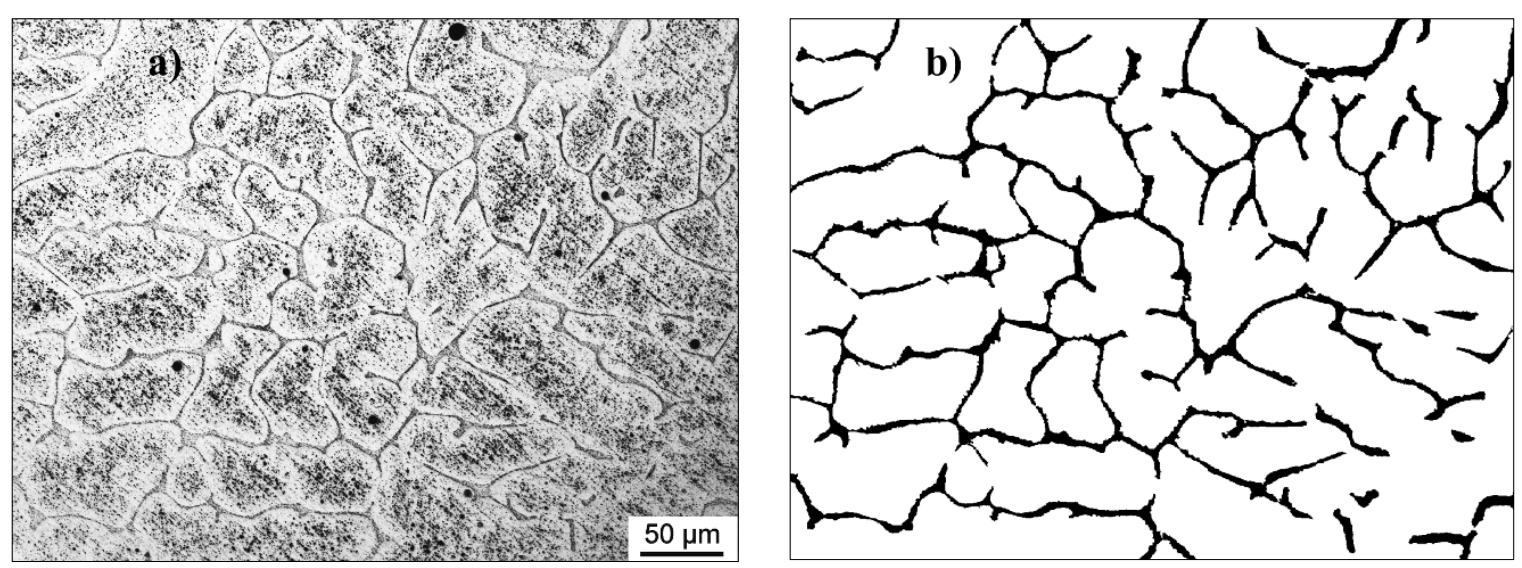

Figure 2 - LOM - a): Microstructure in as-cast condition showing vermicular $\delta$-ferrite (dark grey) in the martensite matrix (light grey); b): Image Analysis - Isolated $\delta$-ferrite (black) extracted from the micrograph in Figure 2a by Image Analysis, yielding a $\delta$-ferrite area-fraction of $11 \%$

\subsubsection{Energy dispersive X-ray spectroscopy}

The EDS measurement across the phase interfaces of two parallel $\delta$-ferrite stringers and martensite (Figure 3a) showed that partitioning between the adjacent phases was most evident for $\mathrm{Cr}$ and $\mathrm{Ni}$ (Figure 3b). The average concentration of $\mathrm{Cr}$ and $\mathrm{Ni}$ within $\delta$ ferrite were 21 and 2.5 wt.\%, respectively. The composition of martensite was close to the average alloy composition and approached the composition of $\delta$-ferrite in a smooth transition across the interface. 
a)

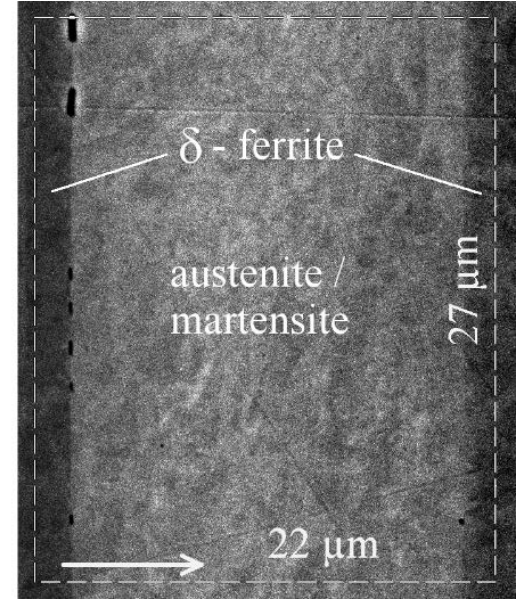

b)

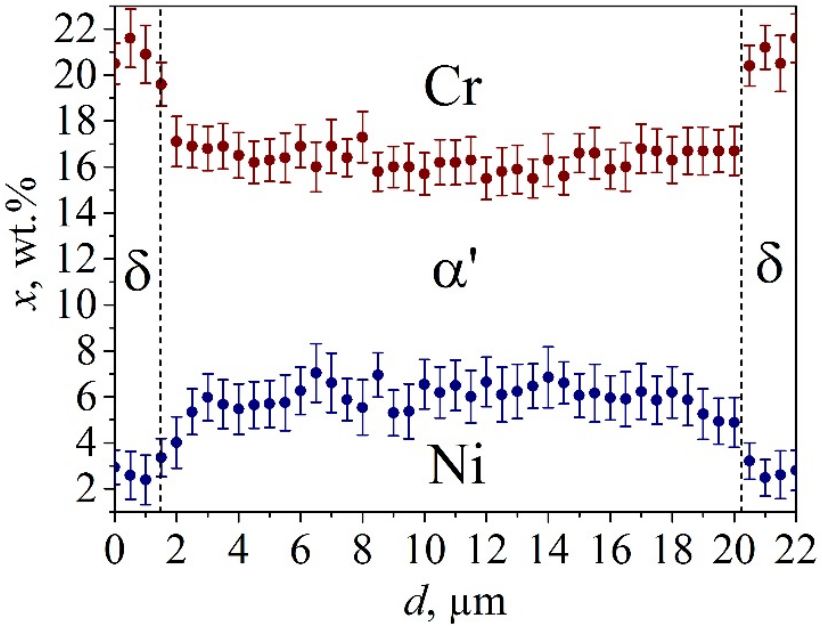

Figure 3 - EDS-Measurements on $\delta / \gamma$-interfaces - a): SEM backscatter micrograph of area scan; b): $\mathrm{Cr}$ - and $\mathrm{Ni}$ - concentration, $x$, integrated and averaged parallel to the $\delta$-ferrite orientation to a 1-dimensional line profile over distance $d$. The error bars indicate the statistical error of the quantification method.

\section{Modeling}

Modeling was applied to study the phase transformations, which led to the characterized microstructure in Figure 2 and 3. The main focus was on the prediction of the solidification reaction and the kinetics analysis of the subsequent solid state phase transformations during cooling. Various models for the prediction of solidification microstructures and phase equilibria are available and the most common ones were evaluated for this purpose.

\subsection{Conventional models}

The Schaeffler-diagram is an empiric model that was established for the prediction of weld-microstructures in 1947 [32]. It predicts phase fractions after solidification and cooling based on the input of $\mathrm{Cr}$ - and Ni-equivalents. The alloy investigated here had Cr- and Ni- equivalents of 17.6 and 6.9 wt.\%, respectively. Due to an appreciable amount of $\mathrm{N}$ in the alloy the modification by DeLong and Reid was evaluated too [33]. It attributes $\mathrm{N}$ the same influence on austenite stability as $\mathrm{C}$, which led to a $\mathrm{Ni}$ equivalent of $9.3 \mathrm{wt} . \%$. The equation of Schaeffler resulted in prediction of martensite with approx. $18 \%$ of retained $\delta$-ferrite and a small fraction of retained austenite. The formulation by DeLong and Reid led to approx. $6 \%$ of retained $\delta$-ferrite and more than $50 \%$ of retained austenite next to martensite (Figure 4 ).

The models, which are presented in the following, are run in Thermo-Calc/DICTRA. All simulations are run with the alloy composition in Table 1, with exclusion of S, P and $\mathrm{N}$. This was done because the trace elements $\mathrm{S}$ and $\mathrm{P}$ are not implemented in the used databases. In the kinetics model including $\mathrm{N}$ led to numerical instability.

Global equilibrium phase fractions as function of temperature (lever rule) during solidification and cooling were modeled by equilibrium calculations in Thermo-Calc 
1 (database TCFE6 [34]; phases: face centered cubic (fcc), body centered cubic (bcc) and 2 liquid). The model predicted solidification to $\delta$-ferrite with a subsequent two phase 3 region of austenite and $\delta$-ferrite, which extended over a span of approx. $250{ }^{\circ} \mathrm{C}$. The 4 liquidus temperature, $T_{\text {liq }}$, and the solidus temperature, $T_{\text {sol }}$, were predicted as 1480 and $5 \quad 1457^{\circ} \mathrm{C}$, respectively (Figure $5 \mathrm{a}$ ). The model gives general predictions on solidification 6 and cooling under thermodynamic equilibrium, but is not able to take the kinetics of the 7 governing phase transformations into account.

8 The Scheil module in Thermo-Calc assesses solidification by a modified version of the 9 Scheil model, that allows rapid diffusion of $\mathrm{C}$ in the liquid and solid ( $f c c$ and $b c c$ ). The model predicted that $\delta$-ferrite was the first phase to form during solidification. $\delta$-ferrite had increased $\mathrm{Cr}$ - and decreased $\mathrm{Ni}$-content relative to the average alloy composition, leading to Ni-enrichment and Cr-depletion in the melt (Figure 5b). Austenite was predicted to nucleate in a peritectic reaction at a fraction solid of $92 \%$, which led to severe partitioning of $\mathrm{Ni}$ and $\mathrm{Cr}$ towards the end of solidification. With this model $T_{\text {liq }}$ and $T_{\text {sol }}$ were predicted as 1481 and $1397^{\circ} \mathrm{C}$, respectively. It is generally known that the Scheil model overestimates segregation towards the end of solidification and is not designed to predict subsequent solid-state phase transformations during cooling [25].

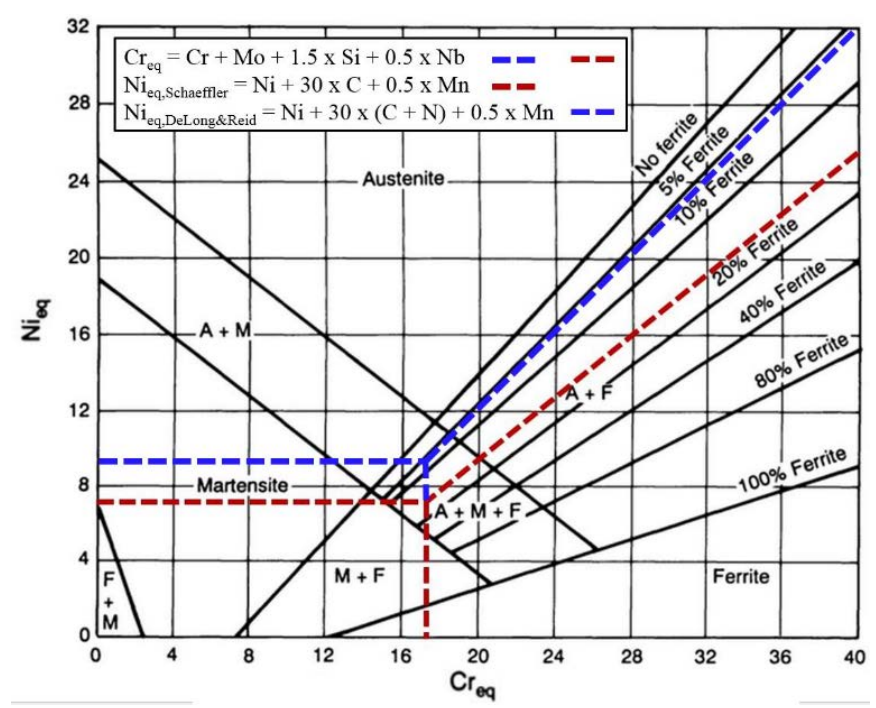

Figure 4 - Schaeffler constitution diagram of 1949 for stainless steel weld metal [36]. The red dashed lines indicate the equivalent compositions and ferrite prediction according to Schaeffler, the blue dashed lines include the effect of $\mathrm{N}$ on the $\mathrm{Ni}_{\text {eq }}$ and the ferrite prediction according to DeLong and Reid [33] 
a)

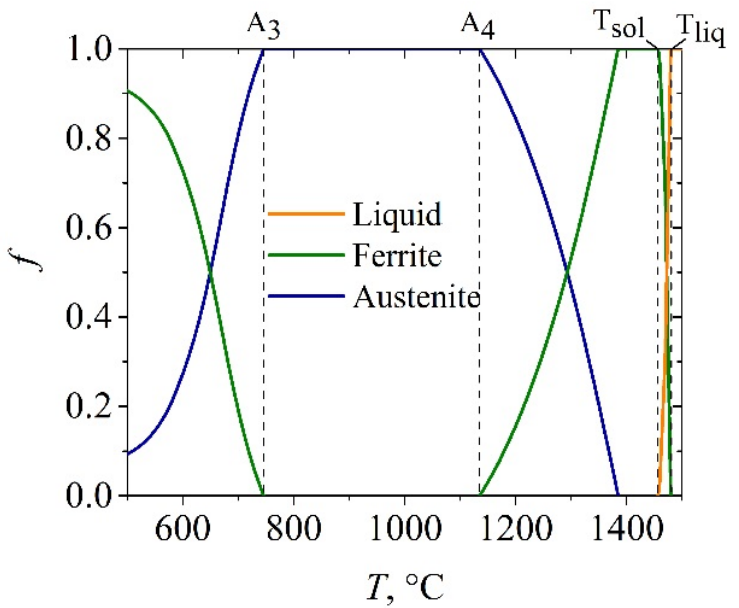

b)

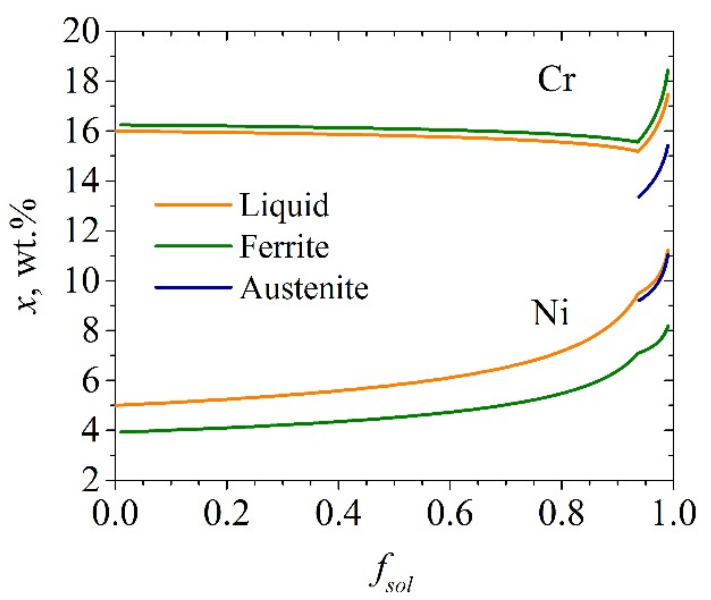

Figure 5 - a): Equilibrium calculation: Phase-fraction, $f$, vs. temperature, $T$, determined by carrying out a step-equilibrium calculation in Thermo-Calc; b): Scheil model: $\mathrm{Cr}$ - and Nicontent $x$, vs. the total solid fraction, $f_{\text {sol, }}$, for the phases liquid, ferrite $(b c c)$ and austenite $(f c c)$

\subsection{Kinetics modeling}

The moving boundary model in the kinetics model DICTRA gives predictions on the kinetics of phase transformations during solidification and cooling [27]. The model is able to overcome most limitations of the previously introduced conventional models by describing movement of the phase boundary, based on the rate of diffusion to and from the interface. Diffusion is modelled by multi-component diffusion equations and assuming local equilibrium at the phase interface. As the model is designed for diffusion controlled transformations only it is not suitable for handling displacive transformations as e.g. martensite formation. [37].

\subsubsection{Model initialization}

The model was initialized with the purpose of predicting the experimentally determined phase distribution and concentration profiles in Figure 3. The solidification front was defined as a one-dimensional planar geometry. The simulation commenced in a liquid domain. The domain size was defined as half the length of the typical $\delta$-ferrite spacing, which in this case was $11 \mu \mathrm{m}$, c.f. Figure 3a. Ferrite was set to nucleate in one end the domain (to the left in Figure 7a). Austenite was set to nucleate on the ferrite-liquid interface, in order to allow a potential peritectic solidification reaction to take place. However, the model did not predict a peritectic reaction, therefore austenite nucleated in the final ferrite (to the right in Figure 7a). All phases were required to overcome a critical driving force for precipitation, $-\mathrm{d} G_{\mathrm{m}} /(R T)$ of $10^{-5}$, where $G_{\mathrm{m}}$ is the molar Gibbs energy, $\mathrm{R}$ is the universal gas constant and $\mathrm{T}$ the temperature in $\mathrm{K}$. This value is a default value in DICTRA and follows the Thermo-Calc/DICTRA convention of defining all driving forces dimensionless [38]. The thermodynamics database TCFE6 [34] and the mobility database MOB2 [39] were used. The choice of spatial and temporal discretization was determined by evaluating the trade-off between spent computational time and reasonable physical representation of the phase transformations. The calculations were thus carried out with a linear spatial resolution of 80 cells, i.e. a 
1 discretization of $137.5 \mathrm{~nm}$, and a maximum time step of $0.1 \mathrm{~s}$. For lower temporal and 2 spatial resolutions numeric instabilities occurred. The stability of the numeric 3 simulation was enhanced by using a fully implicit scheme and by variation of the 4 chemical activities instead of chemical potentials.

5 The kinetics model DICTRA requires the input of cooling rates to simulate the time and 6 temperature dependent phase transformation kinetics. In order to obtain a cooling rate, 7 which resembled the actual cooling rate during casting, a simulation of solidification 8 and cooling of the actual casting geometry was carried out in a casting process 9 modelling software (MAGMA5) using the keel block geometry and with material 10 properties calculated in JMatPro. The procedure for this and application examples are described in Ref. [40-42]. The resulting cooling curve was separated into three parts, each fitted by a $2^{\text {nd }}$ order polynomial fit, which together resulted in the non-linear cooling curve in Figure 6. To analyse the effect of cooling rate on the phase distribution an additional set of four constant cooling rates were selected for input to DICTRA. These four linear cooling curves were chosen so that they matched the varying cooling conditions in the casting process modelling software (see Figure 6).

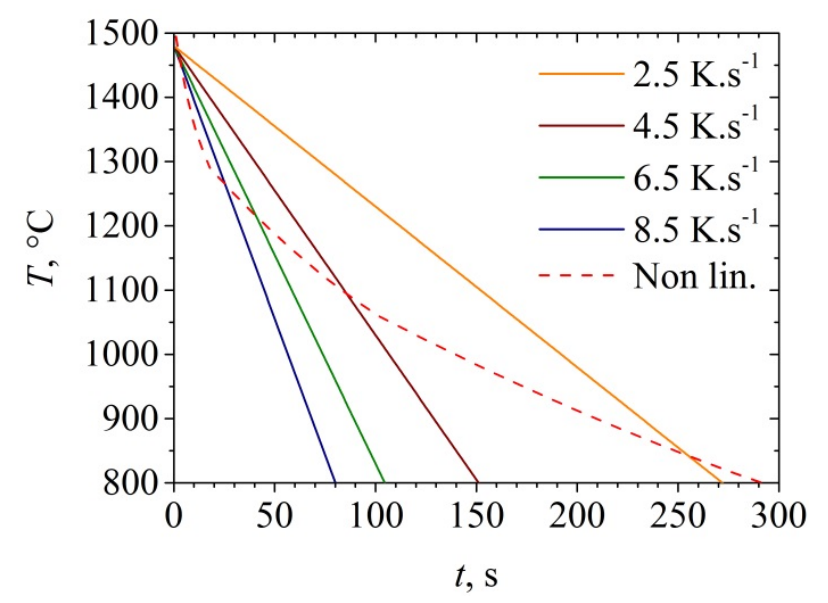

Figure 6 - Non-linear cooling curve modeled with MAGMA5 (red dashed line) and four linear cooling curves (solid lines)

\subsubsection{Solidification and cooling prediction}

According to the kinetics model, the melt solidified as $\delta$-ferrite in the solidification interval $T_{\text {liq }}$ to $T_{\text {sol }}$ of $1480{ }^{\circ} \mathrm{C}$ to $1449{ }^{\circ} \mathrm{C}$. Solidification to $\delta$-ferrite led to microsegregation, but this was homogenized within 2 to $3 \mathrm{~s}$ (corresponding to a temperature change of approx. $70{ }^{\circ} \mathrm{C}$ ) before austenite nucleated. Austenite then formed from $\delta$ ferrite at $1389{ }^{\circ} \mathrm{C}$. Because of the immediate homogenization of $\delta$-ferrite after solidification, the choice of nucleation site, either at the left domain boundary, the right domain boundary, or the right boundary of ferrite, did not affect the nucleation and growth of austenite. Growth of austenite led to significant partitioning of the major alloying elements $\mathrm{Cr}$ and $\mathrm{Ni}$ (Figure 7a), which increased with further cooling. It is noted that the minor alloying elements were also subject to partitioning. The maximum 
1 transformation rate was reached at $1275^{\circ} \mathrm{C}$. Upon further cooling the transformation 2 slowed down and 17 vol. $\%$ of $\delta$-ferrite was retained after cooling to $800{ }^{\circ} \mathrm{C}$ (Figure $7 \mathrm{~b}$ ).

3 At lower temperatures numerical instabilities were experienced.

a)

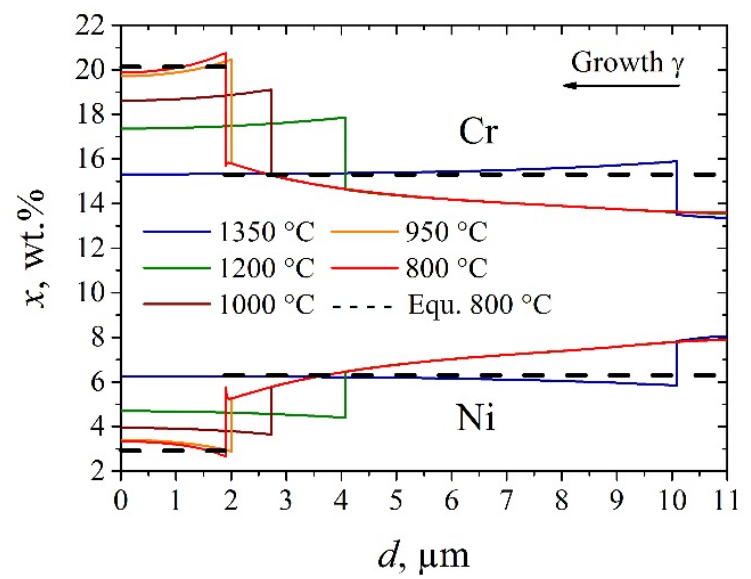

b)

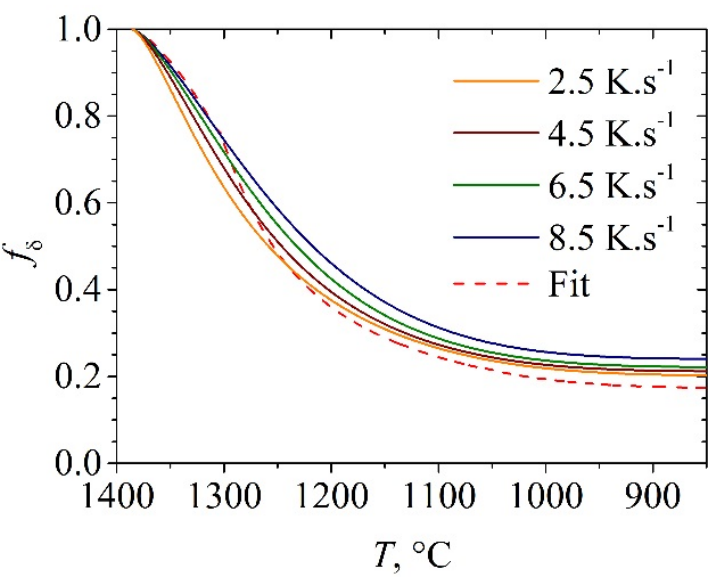

Figure 7 - Kinetics model - a): Isothermal Cr- and Ni-content, $x$, vs. distance, $d$, determined by using kinetics modeling for the non-linear cooling curve in Figure 6 . The phase-interface is at the discontinuity of the concentration profiles. The dashed lines show the global equilibrium contents of metastable ferrite and austenite at $800{ }^{\circ} \mathrm{C}$; b): Volume-fraction of $\delta$-ferrite, $f \delta$, vs. temperature, $T$, for the cooling curves in Figure 6

\subsubsection{Variation of the cooling rate}

Solidification and cooling with four linear cooling rates ranging from 2.5 to $8.5 \mathrm{~K} . \mathrm{s}^{-1}$ were simulated to investigate the effect of the cooling rate on the ferrite to austenite transformation (Figure 6).

The analysis revealed that slower cooling led to lower fractions of retained $\delta$-ferrite (Figure 7b). Comparison of the linear cooling curves with the modeled non-linear cooling curve showed that the maximum transformation rate of ferrite to austenite occurred between 1300 and $1200{ }^{\circ} \mathrm{C}$.

In order to illustrate the kinetics of the described phase transformations and to demonstrate the effect of cooling-rate, the course of the transformations vs. temperature, as shown in Figure 7a for the non-linear cooling curve, is available for the fastest

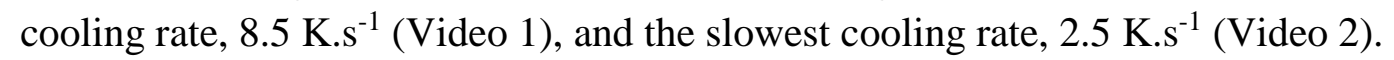

\section{Discussion}

The discussion focuses on the predictions of solidification and cooling obtained from the kinetics model based on the characterized microstructure in Figure 3a and the results from the other evaluated models. An overview of the measured and predicted solidification temperatures and solute partitioning is given in Table 2. 


\subsection{Microstructure evolution during solidification}

2 The kinetics model using the non-linear cooling rate predicted, that the melt solidified 3 entirely as $\delta$-ferrite and the resulting micro-segregation from solidification was 4 homogenized completely within 2 to 3 s of cooling, corresponding to approx. $70{ }^{\circ} \mathrm{C}$, i.e. 5 before the nucleation of austenite. Since the kinetics model simulates the diffusion in 6 the liquid and solid, based on thermodynamic and kinetic quantities the prediction of 7 rapid homogenization is considered to be reliable. The Scheil model, which does not 8 account for back-diffusion of substitutional elements into the solid, predicted severe 9 micro-segregation, especially at the end of solidification. In the case of the present 10 experimental casting, the Scheil model did therefore not give reasonable predictions. 11 The keel block used here is a standard geometry used for validating mechanical 12 properties of medium size stainless steel castings in the industry. It thus represents 13 typical conditions for this class of commercial castings. Commercial castings vary in 14 size and cooling conditions. In large castings diffusion distances can be much larger so 15 that back-diffusion does not occur to any significant degree. Smaller castings will 16 experience higher cooling rates and have a finer microstructure. The kinetics model is 17 applicable for all casting geometries, since it in contrast to the Scheil model, simulates 18 solidification under direct assessment of diffusion distances and cooling rates and thus 19 takes geometrical conditions into account.

20 Both the kinetics model and the lever rule predicted complete solidification to $\delta$-ferrite 21 and subsequent nucleation of austenite, whereas the Scheil model predicted peritectic 22 solidification, in which austenite nucleates at the interface of $\delta$-ferrite and the melt 23 (Figure 5). The deviating prediction of the Scheil model is based on the above 24 mentioned overestimation of micro-segregation. It is apparent from Figure 8 that the 25 different solidification reactions have an influence on the predicted solidus 26 temperatures. The nucleation of austenite in peritectic solidification has a retarding 27 effect on solidification, which is evident from the kink in the Scheil solidification curve 28 at $92 \%$ of solidification (Figure 8). 


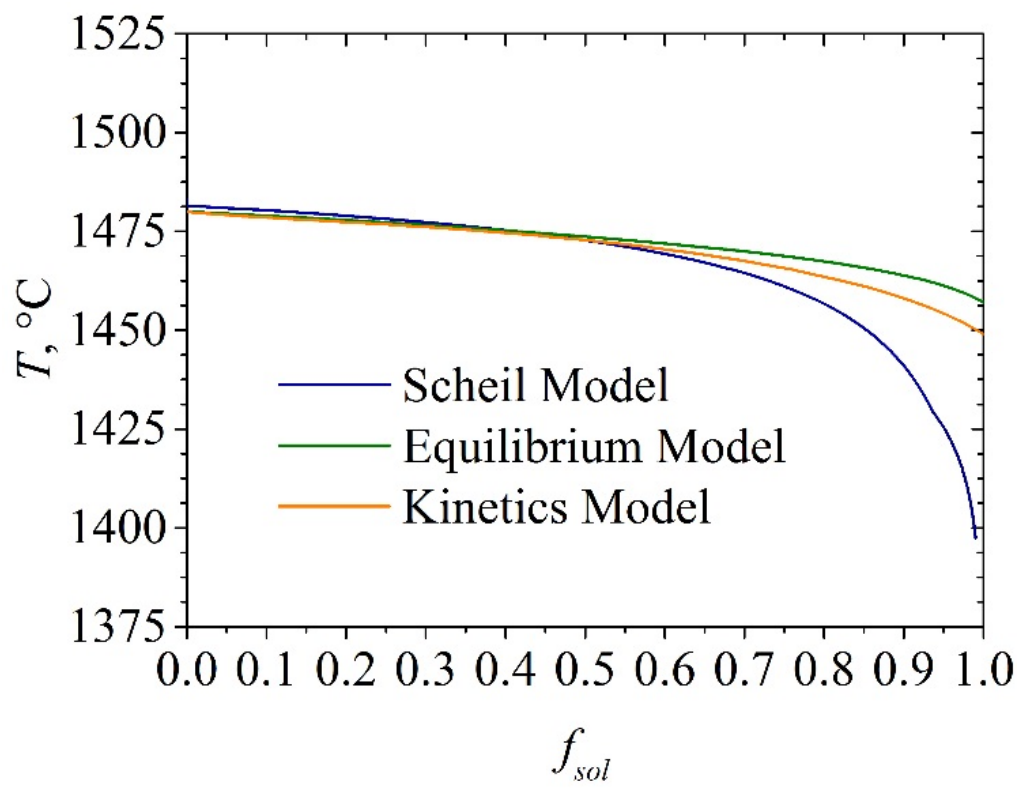

Figure 8 - Comparison of the solidification curves, predicted by using the equilibrium model, the Scheil model and the kinetics model

\subsection{Microstructure evolution during cooling}

\subsubsection{Transformation kinetics and mechanisms}

After solidification to $\delta$-ferrite with almost immediate homogenization of the segregated microstructure, nucleation and growth of austenite at the last solidified material led to severe partitioning during cooling (Figure 7a). The maximum growth rate of austenite was at $1275{ }^{\circ} \mathrm{C}$. Upon further cooling, the growth rate decreased and $\delta$-ferrite was retained (Figure $7 \mathrm{~b})$.

The model showed, that the nucleation and growth kinetics of austenite are independent of the defined nucleation site, because of complete compositional homogenization in $\delta$ ferrite before nucleation of austenite. Assuming that this prediction is valid, austenite is still expected to nucleate at the last solidified melt, as the interfaces of solidified $\delta$ ferrite grains facilitate potent heterogeneous nucleation sites. Such nucleation sites would then imply that retained $\delta$-ferrite in the microstructure in Figure 2a to some degree corresponds to the first solidified material. The $\delta$-ferrite pattern could indeed correspond to the cores of partially transformed $\delta$-ferrite dendrites, as observed for a similar microstructure in Ref. [43]. Alternatively it could resemble a cellular solidification structure, or even a microstructure that is not directly related to the solidification microstructure, but influenced by the temperature gradient during the ferrite to austenite transformation. Further research is required to accurately relate the as-cast microstructure to the solidification microstructure at high temperature.

The initial partitioning after the nucleation of austenite $(f c c)$ led to enrichment of $\mathrm{Cr}$ and depletion of $\mathrm{Ni}$ in ferrite $(b c c)$. In order to achieve full transformation of $\delta$-ferrite to austenite at lower temperature, the concentration profile is required to flatten. This 
1 requires diffusion of $\mathrm{Cr}$ from ferrite into austenite and diffusion of $\mathrm{Ni}$ from austenite 2 into ferrite. It is well known that diffusion of $\mathrm{Ni}$ and $\mathrm{Cr}$ occurs slower in $f c c$ than in bcc

3 [9,44-47]. The decrease of the diffusion rate during cooling thus kinetically freezes the 4 transformation, so that $\delta$-ferrite is retained.

5 The equilibrium calculations revealed a temperature interval of approx. $400{ }^{\circ} \mathrm{C}$ for the 6 austenite single phase region over the cooling sequence (Figure 5a). The strong 7 divergence from the prediction of the equilibrium model and the characterized 8 microstructure emphasizes, that kinetics play a vital role in the ferrite to austenite 9 transformation during cooling, and that the equilibrium based models are thus no 10 appropriate method to predict the as-cast microstructure.

\subsubsection{Fraction of retained $\delta$-ferrite and partitioning}

12 The predicted amount of $17 \mathrm{vol} . \%$ retained $\delta$-ferrite at $800{ }^{\circ} \mathrm{C}$ from the kinetics model is 13 in reasonable agreement with the measured 11 vol.\% (Figure 2) and the predicted 14 concentration profile by applying the kinetics model was in excellent agreement with 15 the measured concentration profile in the as-cast microstructure (Figure 9). Since the 16 concentration gradient in austenite during cooling cannot be fully homogenized, it is 17 retained when the transformation comes to a halt. This gradient, even though less 18 prominent, could be measured with EDS analysis in martensite (Figure 9 ). The $\delta / \gamma$ 19 interface almost completely halted at $800{ }^{\circ} \mathrm{C}$, which implies that no significant change 20 in phase fraction and elemental concentration is to be expected below this temperature 21 (Figure 7b).

22 Discrepancies between the results of the model and the measurements could be caused 23 by the limitation of the model to a single spatial dimension, whereas heat flow, 24 diffusion, and consequently grain growth in fact occur in three dimensions. Furthermore the $\delta$-ferrite area fraction determined by image analysis (Figure 2b) was estimated to comprise a statistical error of $\pm 2 \%$. The amount of predicted retained $\delta$-ferrite by using the kinetics model would certainly have been further reduced, if $\mathrm{N}$ was included in the composition for the kinetics model. As previously stated, this was not possible due to numeric instability. Ma et al. in fact showed in an extensive experimental study that addition of $\mathrm{N}$ is an effective way of reducing the $\delta$-ferrite content in lath martensite, which however promotes formation of $\mathrm{Cr}_{2} \mathrm{~N}$ precipitates during tempering [48]. Also the Schaeffler diagram predicted $18 \% \delta$-ferrite without considering the addition of $\mathrm{N}$, and $6 \% \delta$-ferrite by including the effect of $N$, according to DeLong and Reid [33]. The latter prediction however also led to an extensive overestimation of the stable fraction of austenite.

Another simple method of predicting the composition of $\delta$-ferrite in the as-cast microstructure for the present alloy, was by determining the $\mathrm{Cr}$ and $\mathrm{Ni}$ concentration of metastable ferrite by equilibrium calculations at $800{ }^{\circ} \mathrm{C}$, approx. $50{ }^{\circ} \mathrm{C}$ above the $\mathrm{A}_{3}$ temperature (Figure 5a). The prediction was fairly accurate, because the local equilibrium at the interface approximately followed the global equilibrium (Figure 7a). 
1 Further investigations are necessary to investigate, whether this method is generally

2 applicable to other alloy systems.

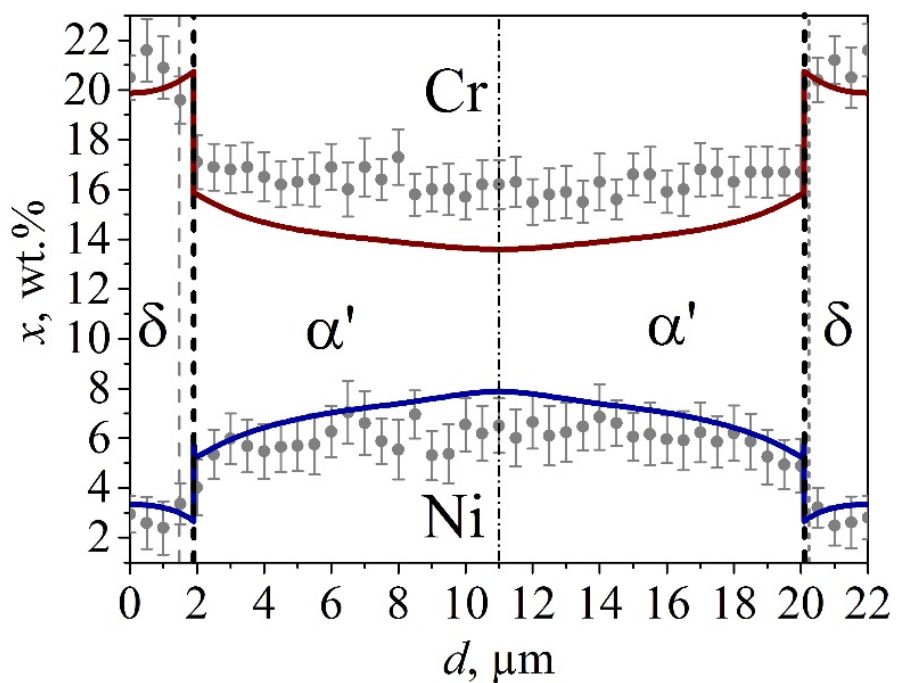

Figure 9 - Comparison of the $\mathrm{Cr}$ and Ni concentration profiles predicted by kinetics modeling at $800{ }^{\circ} \mathrm{C}$ (red and blue line, respectively) and the compositional analysis of two $\delta$-ferrite stringers and martensite by EDS analysis in Figure 3 (grey points).

\subsection{Systematic variation of cooling rate}

Slower cooling led to the prediction of less retained $\delta$-ferrite. The transformation curves in Figure $7 \mathrm{~b}$ show, that the temperature interval of 1300 to $1200{ }^{\circ} \mathrm{C}$ is of particular importance for reducing the amount of retained $\delta$-ferrite. This becomes apparent when analyzing the transformation kinetics of the non-linear cooling rate (Figure 6), which initially is the fastest cooling rate and consequently yields the slowest transformation rate. By a decrease in cooling rate in the interval 1290 to $1200{ }^{\circ} \mathrm{C}$ rapid transformation of ferrite to austenite occurs, which results in the highest transformed fraction at the end of the simulation (Figure $7 \mathrm{~b}$ ). This temperature interval is approx. $100 \mathrm{~K}$ above the $\mathrm{A}_{4}$ temperature, which is the temperature at which $\delta$-ferrite becomes present as a second phase next to austenite in global equilibrium (Figure 5a). The fast transformation in this temperature interval is caused by the concurrent presence of a high driving force for austenite formation and sufficiently high diffusion coefficients to drive the transformation.

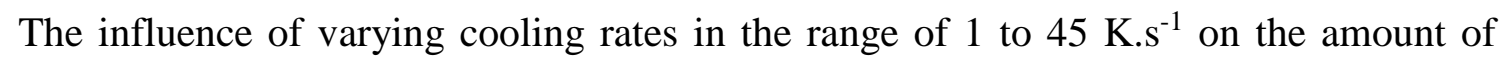
retained $\delta$-ferrite for austenitic stainless steels of various $\mathrm{Cr}$ - and Ni-equivalents was investigated experimentally in Ref. [20]. It was concluded that the composition had the strongest influence on the amount of $\delta$-ferrite. Furthermore slower cooling, when fully solidifying as $\delta$-ferrite or in a peritectic reaction, led to smaller fractions of retained $\delta$ ferrite. The authors concluded that the time spent in the $\gamma+\delta$ two phase region was responsible for this effect. This temperature region is in excellent agreement with the identified temperature interval of 1300 to $1200^{\circ} \mathrm{C}$ by using kinetics modeling. 
1 This observation has important implications for practical possibilities of homogenizing

2 a casting, after $\delta$-ferrite has been retained during cooling. Since the temperature region

3 of fastest $\delta$-ferrite to austenite transformation rate is not within the austenite single

4 phase region and practically difficult to achieve in industrial heat-treatments, it is not

5 possible to fully transform $\delta$-ferrite within this region. Consequently the temperature

6 range below the $A_{4}$-temperature has to be applied, which facilitates rather slow

7 transformation kinetics. Thus it is of great importance to avoid the retainment of $\delta$ -

8 ferrite from solidification and initial cooling, and kinetics modeling can be used as a

9 tool to achieve this. Research on the application of kinetics modeling to predict the

10 kinetics of homogenization of $\delta$-ferrite after solidification is ongoing.

11 Close to $800{ }^{\circ} \mathrm{C}$ the $\mathrm{A}_{3}$-temperature of $746{ }^{\circ} \mathrm{C}$ is approached, which corresponds to a 12 steady increase of the driving force for ferrite formation. This may have contributed to 13 the instability of the simulations, which were run below $800{ }^{\circ} \mathrm{C}$.

\subsection{Relation between domain size and cooling rate}

The kinetics model predictions for a certain cooling rate were found to depend strongly on the chosen domain size. At too large domain sizes relative to the cooling rate the transformation halts before soft impingement takes place at the $\delta$-ferrite centerline, which leads to too high predictions of the $\delta$-ferrite phase fraction and strong concentration profiles inside the $\delta$-ferrite.

In reality, the domain size is coupled to the cooling rate. Solidification theory states that the secondary dendrite arm spacing, which is anticipated to be directly or indirectly related to the $\delta$-ferrite spacing, and thus half the simulation domain, is inversely proportional to the square root of the liquid/solid interface velocity, which is determined by the cooling rate [49].

In the present analysis the measured $\delta$-ferrite spacing of $22 \mu \mathrm{m}$ was adequate in relation to the modelled cooling rates. Experiments to calibrate the relation between cooling rate and $\delta$-ferrite spacing, as well as the relation of the $\delta$-ferrite to the solidification microstructure at high temperature, are planned for future research.

\section{Conclusion}

30 Solidification and cooling of GX-CrNiMo-16-5-1 cast supermartensitic stainless steel were analyzed by applying the kinetics model DICTRA. The results were compared to results of empirical and thermodynamic models and validated on micrographs and EDS analysis of the as-cast microstructure of an ingot.

The main conclusions are:

(1) The kinetics model could predict the kinetics of phase transformations during solidification and cooling. It illuminated the mechanism of $\delta$-ferrite retainment 
1 comprehensively and predicted the locally measured amount and composition of $\delta$ ferrite and austenite after solidification and cooling reasonably well.

(2) The kinetics model predicted that micro-segregation originating from solidification is homogenized within $2-3 \mathrm{~s}$ of cooling $\left(70{ }^{\circ} \mathrm{C}\right)$ after solidification, and that the impinged diffusion field of the $\delta$-ferrite to austenite solid state transformation causes the compositional inhomogeneity in the cast microstructure.

(3) The kinetics model showed that slower cooling leads to less retained $\delta$-ferrite. The amount of time spent between 1300 and $1200{ }^{\circ} \mathrm{C}$ was found to be most effective for transformation of $\delta$-ferrite to austenite, which is in excellent agreement with experimental data.

(4) Calculation of the global equilibrium composition of metastable $\delta$-ferrite at $800{ }^{\circ} \mathrm{C}$, approx. $50{ }^{\circ} \mathrm{C}$ below the $A_{3}$-temperature, was found as a simple method to predict the phase composition at room temperature for the present alloy.

(5) Soft impingement at the $\delta$-ferrite centerline was found to be necessary for accurate predictions of the kinetics model. Therefore the model domain size needs to be calibrated in dependence of the cooling rate. This dependence might be equivalent to the relationship between the secondary dendrite arm spacing and the solidification rate in casting.

\section{Acknowledgements}

20 The authors would like to thank Frese Metal- \& Stålstøberi A/S for providing the 21 examined cast material. The Danish Underground Consortium is gratefully 22 acknowledged for financial support to the Danish Hydrocarbon Research Center 23 (DHRTC). 


\section{References}

[1] G. Baggström, New Steel for Turbine Runners, Water Power. 16 (1964) 516521.

[2] M. Grounes, S. Rao, New Alloy Steels for Nuclear Reactor Pressure Vessels and Vessel Internals, Trans. ASM. 62 (1969) 902-914.

[3] P.E. Kvaale, O. Stein, Experience with supermartensitic stainless steels in flowline applications, in: Stainl. Steel World 99, 1999: pp. 19-26.

[4] A.W. Marshall, J.C.M. Farrar, Welding of Ferritic and Martensitic 11-14\% Cr Steels, Weld. World. 45 (2001) 19-42.

[5] L.M. Smith, M. Celant, Martensitic stainless steel flowlines - Do they pay?, in: Supermartensitic Stainl. Steels 1999, 1999: pp. 66-73.

[6] H.J. Niederau, A New Low-Carbon 16Cr-5Ni Stainless Martensitic Cast Steel, in: G. Behal, A.S. Melilli (Eds.), Stainl. Steel Cast., ASTM, Bal Harbour, Florida, 1982: pp. 382-393.

[7] P. Brezina, B. Sonderegger, Wärmebehandlung, Gefüge und Eigenschaften des korrosionsträgen martensitaushärtbaren Stahles X 5 CrNiMoCuNb 145 (14-5 PU), Härterei-Technische Mitteilungen. 33 (1978) 1-12.

[8] F. Niessen, M. Villa, D. Apel, O. Keßler, M. Reich, J. Hald, et al., In situ techniques for the investigation of the kinetics of austenitization of supermartensitic stainless steel, Mater. Sci. Forum. 879 (2017) 1381-1386. doi:10.4028/www.scientific.net/MSF.879.1381.

[9] F. Niessen, M. Villa, J. Hald, M.A.J. Somers, Kinetics analysis of two-stage austenitization in supermartensitic stainless steel, Mater. Des. 116 (2017) 8-15. doi:10.1016/j.matdes.2016.11.076.

[10] P.D. Bilmes, M. Solari, C.. Llorente, Characteristics and effects of austenite resulting from tempering of $13 \mathrm{Cr}-\mathrm{NiMo}$ martensitic steel weld metals, Mater. Charact. 46 (2001) 285-296. doi:10.1016/S1044-5803(00)00099-1.

[11] Y.-K. Lee, H.-C. Shin, D.-S. Leem, J.-Y. Choi, W. Jin, C.-S. Choi, Reverse transformation mechanism of martensite to austenite and amount of retained austenite after reverse transformation in Fe-3Si-13Cr-7Ni (wt-\%) martensitic stainless steel, Mater. Sci. Technol. $19 \quad$ (2003) 393-398. doi:10.1179/026708303225009742.

[12] W. Jiang, D. Ye, J. Li, J. Su, K. Zhao, Reverse Transformation Mechanism of Martensite to Austenite in 00Cr15Ni7Mo2WCu2 Super Martensitic Stainless Steel, Steel Res. Int. 85 (2014) 1150-1157. doi:10.1002/srin.201300264.

[13] W. Jiang, K. Zhao, D. Ye, J. Li, Z. Li, J. Su, Effect of Heat Treatment on Reversed Austenite in Cr15 Super Martensitic Stainless Steel, J. Iron Steel Res. Int. 20 (2013) 61-65. doi:10.1016/S1006-706X(13)60099-0.

[14] A. Bojack, L. Zhao, J. Sietsma, Thermodynamic Analysis of the Effect of Compositional Inhomogeneity on Phase Transformations in a 13Cr6Ni2Mo Supermartensitic Stainless Steel, Solid State Phenom. 172-174 (2011) 899-904. doi:10.4028/www.scientific.net/SSP.172-174.899.

[15] G. Blanc, R. Tricot, Solidification, ségrégation et homogénéisation des aciers 
inoxydables austénitiques contenant de la ferrite delta, Mém. Et. Sci. Rev. Métall. 68 (1971) 735-753.

[16] P. Wang, S.P. Lu, N.M. Xiao, D.Z. Li, Y.Y. Li, Effect of delta ferrite on impact properties of low carbon 13Cr-4Ni martensitic stainless steel, Mater. Sci. Eng. A. 527 (2010) 3210-3216. doi:10.1016/j.msea.2010.01.085.

[17] S.K. Bhambri, Intergranular fracture in $13 \mathrm{wt} \%$ chromium martensitic stainless steel, J. Mater. Sci. 21 (1986) 1741-1746.

[18] T. Hara, H. Asahi, Effect of d-Ferrite on Sulfide Stress Cracking in a Low Carbon 13 mass\% Chromium Steel., ISIJ Int. 40 (2000) 1134-1141. doi:10.2355/isijinternational.40.1134.

[19] S.H. Kim, H.K. Moon, T. Kang, C.S. Lee, Dissolution kinetics of delta ferrite in AISI 304 stainless steel produced by strip casting process, Mater. Sci. Eng. A. 356 (2003) 390-398. doi:10.1016/S0921-5093(03)00152-7.

[20] O.J. Pereira, J. Beech, The effect of cooling rate and heat treatment on the dferrite content of cast austenitic stainless steels, Br. Founrdryman. 73 (1980) 324-329.

[21] M.A. Martorano, C.F. Tavares, A.F. Padilha, Predicting Delta Ferrite Content in Stainless Steel Castings, ISIJ Int. 52 (2012) 1054-1065. doi:10.2355/isijinternational.52.1054.

[22] S.K.. Kim, Y.K.. Shin, N.J. Kim, Distribution of d-ferrite content in continuously cast type 304 stainless steel slabs, Ironmak. Steelmak. 22 (1995) 316-325.

[23] Q. Chen, B. Sundman, Computation of Partial Equilibrium Solidification with Complete Interstitial and Negligible Substitutional Solute Back Diffusion., Mater. Trans. 43 (2002) 551-559. doi:10.2320/matertrans.43.551.

[24] P.K. Palani, N. Murugan, Comparison of regression and artificial neural network models for prediction of delta ferrite content in stainless steel claddings, Int. J. Knowledge-Based Intell. Eng. Syst. 10 (2006) 433-443.

[25] M. Vasudevan, A.K. Bhaduri, B. Raj, K. Prasad Rao, Delta ferrite prediction in stainless steel welds using neural network analysis and comparison with other prediction methods, J. Mater. Process. Technol. 142 (2003) 20-28. doi:10.1016/S0924-0136(03)00430-8.

[26] M.A.V. Bermejo, Predictive and Measurement Methods for Delta Ferrite Determination, Weld. J. 91 (2012) 113-121.

[27] H. Larsson, A model for 1D multiphase moving phase boundary simulations under local equilibrium conditions, Calphad Comput. Coupling Phase Diagrams Thermochem. 47 (2014) 1-8. doi:10.1016/j.calphad.2014.06.001.

[28] J.R. Vilella, Delving into metal structures, Iron Age. 117 (1926) 761-763.

[29] K.V. Dahl, J. Hald, A. Horsewell, Grey-scale conversion X-ray mapping by EDS of multielement and multiphase layered microstructures., J. Microsc. 225 (2007) 31-40. doi:10.1111/j.1365-2818.2007.01713.x.

[30] A.Y. Jang, D.J. Lee, S.H. Lee, J.H. Shim, S.W. Kang, H.W. Lee, Effect of Cr/Ni equivalent ratio on ductility-dip cracking in AISI 316L weld metals, Mater. Des. 32 (2011) 371-376. doi:10.1016/j.matdes.2010.06.016.

[31] H. Kokawa, T. Kuwana, a Yamamoto, Crystallographic Characteristics of Delta- 
Ferrite Transformations in a 304L Weld Metal at Elevated Temperatures, Weld. J. 68 (1989) 92s-101s.

[32] A.L. Schaeffler, Selection of Austenitic Electrodes for Welding Dissimilar Metals, Weld. J. 26 (1947) 601-621.

[33] D.L. Olson, Prediction of Austenitic Weld Metal Microstructure and Properties, Weld. J. 64 (1985) 281-295.

[34] Thermo-Calc Software TCFE6 Steels/Fe-alloys database version 6.2 (accessed November 2009), (n.d.).

[35] K. Chandrasekaran, N.S. Tiedje, J. Hald, Solidification paths in modified Inconel 625 weld overlay material, Int. J. Cast Met. Res. 22 (2009) 306-310.

[36] D.J. Kotecki, Welding of Stainless Steels, in: Welding, Brazing Solder. Vol.6 ASM-Handbook, ASM-International, 1993: pp. 677-707.

[37] A. Borgenstam, A. Engström, L. Höglund, J. Ågren, DICTRA, a tool for simulation of diffusional transformations in alloys, J. Phase Equilibria. 21 (2000) 269-280. doi:10.1361/105497100770340057.

[38] M. Selleby, M. Hillert, Additional problems to the book Phase Equilibria, Phase Diagrams and Phase Transformations, Problem 3.7. Evaluation of the driving force, (2007).

[39] Thermo-Calc Software TCS Alloys Mobility Database MOB2 (accessed 08 April 1998), (n.d.).

[40] MAGMA5, Version 5.3 User Handbook, (2015).

[41] N.K. Vedel-Smith, J. Rasmussen, N.S. Tiedje, Thermal distortion of disc-shaped ductile iron castings in vertically parted moulds, J. Mater. Process. Technol. 217 (2015) 262-271. doi:10.1016/j.jmatprotec.2014.11.025.

[42] P. Kotas, C.C. Tutum, J. Thorborg, J.H. Hattel, Elimination of hot tears in steel castings by means of solidification pattern optimization, Metall. Mater. Trans. B Process Metall. Mater. Process. Sci. 43 (2012) 609-626. doi:10.1007/s11663011-9617-z.

[43] C.C. Hsieh, X. Guo, C.M. Chang, W. Wu, Dendrite evolution of delta (d) ferrite and precipitation behavior of sigma (s) phase during multipass dissimilar stainless steels welding, Met. Mater. Int. 16 (2010) 349-356. doi:10.1007/s12540-010-0602-X.

[44] F.S. Buffington, K. Hirano, M. Cohen, Self diffusion in iron, Acta Metall. 9 (1961) 434-439. doi:10.1016/0001-6160(61)90137-7.

[45] K. Hirano, M. Cohen, B.L. Averbach, Diffusion of Nickel into Iron, Acta Metall. 9 (1961) 440-445.

[46] B. Jönsson, Assessment of the Mobilities of $\mathrm{Cr}, \mathrm{Fe}$ and $\mathrm{Ni}$ in fcc Cr-Fe-Ni Alloys, Zeitschrift Für Met. $86 \quad$ (1995) 686-692. doi:10.2355/isijinternational.35.1415.

[47] B. Jönsson, Assessment of the Mobilities of $\mathrm{Cr}, \mathrm{Fe}$ and $\mathrm{Ni}$ in bcc Cr-Fe-Ni Alloys, ISIJ Int. 35 (1995) 1415-1421. doi:10.2355/isijinternational.35.1415.

[48] X.P. Ma, L.J. Wang, B. Qin, C.M. Liu, S.V. Subramanian, Effect of N on microstructure and mechanical properties of 16Cr5Ni1Mo martensitic stainless steel, Mater. Des. 34 (2012) 74-81. doi:10.1016/j.matdes.2011.07.064. 
[49] H. Frederiksson, U. Ålkerlind, Materials Processing during Casting, Wiley, 2006. 


\section{Tables}

Table 1- Chemical composition of the investigated alloy GX-CrNiMo-16-5-1 balanced with Fe (wt\%) from optical emission spectroscopy (OES)

\begin{tabular}{ccccccccc}
$\mathrm{C}$ & $\mathrm{N}$ & $\mathrm{Cr}$ & $\mathrm{Ni}$ & $\mathrm{Mo}$ & $\mathrm{Mn}$ & $\mathrm{Si}$ & $\mathrm{P}$ & $\mathrm{S}$ \\
\hline \hline 0.011 & 0.078 & 15.30 & 6.30 & 1.22 & 0.58 & 0.70 & 0.013 & 0.006 \\
\hline
\end{tabular}

Table 2 - Comparison of characteristic temperatures, phase fractions and solute contents obtained from the modeled and experimental results; the solute contents represent the average within the respective phases

\begin{tabular}{|c|c|c|c|c|c|c|c|}
\hline & $\mathrm{T}_{\text {liq }}\left[{ }^{\circ} \mathrm{C}\right]$ & $T_{\text {sol }}\left[{ }^{\circ} \mathrm{C}\right]$ & $f_{\delta}[\mathrm{v} . \%]$ & $\begin{array}{l}X \delta, C r \\
\text { [wt.\%] }\end{array}$ & $\begin{array}{l}X \delta, N i \\
\text { [wt.\%] }\end{array}$ & $\begin{array}{l}x_{\gamma, C r} \\
\text { [wt.\%] }\end{array}$ & $\begin{array}{l}x_{\gamma, N i} \\
\text { [wt.\%] }\end{array}$ \\
\hline Schaeffler: & - & - & $18^{\mathrm{a}}$ & - & - & - & - \\
\hline DeLong, Reid: & - & - & $6^{\mathrm{a}}$ & - & - & - & - \\
\hline Equilibrium Model: & 1480 & 1457 & - & $20.1^{\mathrm{b}}$ & $2.9^{b}$ & $15.3^{b}$ & $6.3^{b}$ \\
\hline Scheil Model: & 1481 & 1397 & - & $16.4^{\mathrm{c}}$ & $6.2^{c}$ & $14.4^{\mathrm{c}}$ & $10.1^{\mathrm{C}}$ \\
\hline Kinetics Model: & 1480 & 1449 & $17^{\mathrm{b}}$ & $20.1^{\mathrm{b}}$ & $3.2^{\mathrm{b}}$ & $14.7^{\mathrm{b}}$ & $6.5^{\mathrm{b}}$ \\
\hline Experimental: & - & - & $11^{\mathrm{a}}$ & $21.0^{\mathrm{a}}$ & $2.7^{\mathrm{a}}$ & $16.4^{\mathrm{a}}$ & $5.9^{\mathrm{a}}$ \\
\hline
\end{tabular}

$T_{\text {liq }}$ : Liquidus temperature; $T_{\text {sol }}$ : Solidus temperature; $f_{\delta}$. Fraction of $\delta$-ferrite; $x_{\text {phase,component: Solute }}$ content of component in phase; ${ }^{a}$ : At room temperature; ${ }^{b}$ : at $800^{\circ} \mathrm{C}$; ${ }^{\text {c: }}$ at $\mathrm{T}_{\text {sol }}$ of Scheil Model 


\section{List of Figure captions}

Figure 1 - Geometry of the ingot marking the area of investigation below the cutting plane. Measures are in $\mathrm{mm}$

Figure $2-\mathrm{LOM}-\mathrm{a}$ ): Microstructure in as-cast condition showing vermicular $\delta$-ferrite (dark grey) in the martensite matrix (light grey); b): Image Analysis - Isolated $\delta$-ferrite (black) extracted from the micrograph in Figure 2a by Image Analysis, yielding a $\delta-$ ferrite area-fraction of $11 \%$

Figure 3 - EDS-Measurements on $\delta / \gamma$-interfaces $-a)$ : SEM backscatter micrograph of area scan; b): Cr- and Ni- concentration, $\mathrm{x}$, integrated and averaged parallel to the $\delta$ ferrite orientation to a 1-dimensional line profile over distance $d$. The error bars indicate the statistical error of the quantification method.

Figure 4 - Schaeffler constitution diagram of 1949 for stainless steel weld metal [36]. The red dashed lines indicate the equivalent compositions and ferrite prediction according to Schaeffler, the blue dashed lines include the effect of $\mathrm{N}$ on the Nieq and the ferrite prediction according to DeLong and Reid [33]

Figure 5 - a): Equilibrium calculation: Phase-fraction, f, vs. temperature, T, determined by carrying out a step-equilibrium calculation in Thermo-Calc; b): Scheil model: Crand Ni-content $\mathrm{x}$, vs. the total solid fraction, fsol, for the phases liquid, ferrite (bcc) and austenite (fcc)

Figure 6 - Non-linear cooling curve modeled with MAGMA5 (red dashed line) and four linear cooling curves (solid lines)

Figure 7 - Kinetics model - a): Isothermal Cr- and Ni-content, x, vs. distance, d, determined by using kinetics modeling for the non-linear cooling curve in Figure 6. The phase-interface is at the discontinuity of the concentration profiles. The dashed lines show the global equilibrium contents of metastable ferrite and austenite at $800{ }^{\circ} \mathrm{C}$; b): Volume-fraction of $\delta$-ferrite, $\mathrm{f}_{\delta}$, vs. temperature, T, for the cooling curves in Figure 6

Figure 8 - Comparison of the solidification curves, predicted by using the equilibrium model, the Scheil model and the kinetics model

Figure 9 - Comparison of the $\mathrm{Cr}$ and $\mathrm{Ni}$ concentration profiles predicted by kinetics modeling at $800{ }^{\circ} \mathrm{C}$ (red and blue line, respectively) and the compositional analysis of two $\delta$-ferrite stringers and martensite by EDS analysis in Figure 3 (grey points) 


\section{List of Video captions}

Video 1 - Prediction of $\mathrm{Cr}$ and $\mathrm{Ni}$ content and phase fractions vs. temperature during solidification and cooling at $8.5 \mathrm{~K} . \mathrm{s}^{-1}$ cooling rate by kinetics modeling

Video 2 - Prediction of $\mathrm{Cr}$ and $\mathrm{Ni}$ content and phase fractions vs. temperature during solidification and cooling at $2.5 \mathrm{~K} . \mathrm{s}^{-1}$ cooling rate by kinetics modeling 


\section{List of Interactive Data}

Fig3b.csv - Cr and Ni content measured over two $\delta$-ferrite stringers and martensite by EDS

Fig5a.csv - Equilibrium calculation of phase-fraction, $f$, vs. temperature, $T$, determined by carrying out a step-equilibrium calculation in Thermo-Calc

Fig5b.csv - Cr- and Ni-content $x$, vs. the total solid fraction, fsol, for the phases liquid, ferrite ( $b c c)$ and austenite $(f c c)$ determined by the Scheil model

Fig6.csv - Non-linear cooling curve modeled with MAGMA5

Fig7a_800degC.csv - Cr- and Ni-content, $x$, vs. distance, $d$, at $800{ }^{\circ} \mathrm{C}$ determined by using kinetics modeling for the fitted cooling curve in Figure 6. The phase-interface is at the discontinuity of the concentration profiles.

Fig7a_950degC.csv - Cr- and Ni-content, $x$, vs. distance, $d$, at $950{ }^{\circ} \mathrm{C}$ determined by using kinetics modeling for the fitted cooling curve in Figure 6. The phase-interface is at the discontinuity of the concentration profiles.

Fig7a_1000degC.csv - Cr- and Ni-content, $x$, vs. distance, $d$, at $1000{ }^{\circ} \mathrm{C}$ determined by using kinetics modeling for the fitted cooling curve in Figure 6. The phase-interface is at the discontinuity of the concentration profiles.

Fig7a_1200degC.csv - Cr- and Ni-content, $x$, vs. distance, $d$, at $1200{ }^{\circ} \mathrm{C}$ determined by using kinetics modeling for the fitted cooling curve in Figure 6. The phase-interface is at the discontinuity of the concentration profiles.

Fig7a_1350degC.csv - Cr- and Ni-content, $x$, vs. distance, $d$, at $1350{ }^{\circ} \mathrm{C}$ determined by using kinetics modeling for the fitted cooling curve in Figure 6. The phase-interface is at the discontinuity of the concentration profiles.

Fig7b.csv - Volume-fraction of $\delta$-ferrite, $f \delta$, vs. temperature, $T$, for the cooling curves in Figure 6 determined by using kinetics modeling

Fig8.csv - Comparison of the solidification curves, predicted by using the equilibrium model, the Scheil model and the kinetics model 